\title{
Postscript \\ Fur, feather, teeth and skin: How do technologies and ontologies meet in time and space?
}

\author{
Lindsay Hamilton \\ York Management School, York University, UK \\ lindsay.hamilton@york.ac.uk
}

\begin{abstract}
The old lady cradles her bleeding finger and staggers, feinting almost falling, as Gary from number one sprints back to his garden to pick up a deckchair for her. Her dog, a tiny Yorkshire Terrier, is quivering in another neighbour's arms, snapping at well-wishers who are trying to inspect the skin for any bite-marks. "Has it attacked before?" the old lady quavers, pointing limply to the Jack Russell held by a piece of string in a little boy's sweaty hand. "It's your dog, she's bitten this lady" says Gary as I join the scene, "Your son brought the dog out, but it got loose somehow and went for this little dog. This lady put her hand down to pick her dog up, and she's been bitten." Fearful, the little boy walks away. The old lady is now slumped in the deckchair. Nobody speaks for a while. But then there is talk of tetanus shots and hospitals. "My husband has just had a stroke, you know? This won't help" the old woman says, "I don't know why but dogs always go for my little Misty." I don't apologise though I try to show kindness. After the lady has drunk a cup of tea, used someone's mobile phone to call the doctor and obtained a lift home we all return to what we were doing. As we turn to leave the scene, one of the neighbours comments that "it's such a shame because she is clearly a doglover" which puzzles me. Gary takes his deckchair home.
\end{abstract}

When you research human-animal relations, you observe from the world what you can. The brief incident described above took place outside my back gate on a warm afternoon in May

\footnotetext{
${ }^{1}$ From fieldnotes, May 2019.
}

(C) 2019 Lindsay Hamilton. This is an open access article licensed under the Creative Commons Attribution-NonCommercial-NoDerivs License (http://creativecommons.org/licenses/by-nc-nd/3.0/). 
2019. Read as a brief ethnographic vignette, there was more going on than a momentary meeting between canine teeth and human skin; there was talk of violence, vaccinations, control and blame. There were mobile phones, cups of tea, deckchairs and string. The words as well as the materials were telling a story. When participants spoke, the Jack Russell was an "it" but also an attacker, minded to get loose; a roving "thing" on the lookout for trouble. Both object and agent. Yet Misty, the serial victim, seemed more human than animal, the language elevating her morally above her counterpart. Despite this paradox, Misty's owner was described as a "dog lover" and perhaps because of that unresolved contradiction, I could not bring myself to apologise; after all, my Jack Russell wasn't - or perhaps didn't have the capacity to be - sorry. Actually, both terriers seemed oblivious to the highly charged scene unfolding around them and the very different roles into which they had unwittingly been cast.

In this as any other tale from the field, actions, words and materials contour the way humans refer to the animals that they are surrounded by. In paradoxical depictions of personality, agency and mindedness are the traces of broader social concepts of animality. Those attuned to the symbolism can see animal typographies surface and dive: "the devoted lap-dog," the "aggressive terrier," "the pest," the "swarm." There are also persistent paradoxes that enable some humans to be cast as "dog lovers" and yet refer to unfamiliar dogs as "attackers" or "things." Of course, none of these labels adequately capture the complexity of socio-technical situations as they emerge. What they do offer, however, is a sort of semiotic shorthand that helps humans to make sense of the world, describe it and thereby impose structure on the teeming, seething milieu of the unorganisable, nonhuman "other."

This is how the playbook that casts some creatures as vermin, some as worthy of ownership/ pet-hood, others as test subjects or food is re-inscribed and becomes powerful over time. In noting this, it is important to be mindful of the limitations of our own species knowledge as well as our inhabitation of highly particular cultural epochs. For what can we truly know of these encounters and worlds except through the lens that we turn to the world around us? A lens ground through culture and language makes it hard to see interspecies meetings outside the historical framework in which they emerge. How do the objects, actors and discourses work together to make meaning for us as participants and observers? What are the epistemic limits of our humanism, our scientific heritage and our living cultural world? These are the philosophical and practical challenges that human-animal studies of various sorts seek to grapple with. They inform the critical core of the special issue that you have just read, a volume which investigates a plethora of multi-species encounters mediated by organisations and ontologies in time and space. 
In Amanda Rees's opening account of the development of socio-technical strategies and practices used to study and to display whales, dolphins and seals, we witnessed a careful historical exposition of the emergence of new styles of learning about marine animal behaviour and biology. This initial piece foregrounded some deep philosophical issues by resisting the notion of marine biology as a "pure" scientific endeavour, but instead showed how its practises and values intertwine with social and political history. Here, then, are the influences of colonialism, structuring marine mammal-human intersections; shaping science as both a profession and a form of knowledge with its own distinct methods of learning. Rob Kirk's account of laboratory monkeys then opened a complimentary critique of scientific knowledge acquisition; one infused by ethical dilemmas, legal structures, media storytelling and public opinion on the costs and benefits of new scientific breakthroughs. The Silver Spring monkey controversy was not a paradigm war between scientific methodology and accepted social norms about animal care and treatment but, like the preceding article, a social, historical moment infused by the transient politics of knowledge. The account suggests a nuanced meeting between historically distinct cultures in which animals are known differently by experts of various stripes.

Maisie Tomlinson then drew our attention to the emergence of a relatively recent scientific technique - Qualitative Behavioural Assessment - for learning about animal actions and emotions. This development supported a new form of language about animals; words which both mirrored and challenged powerful norms in society. Through scientific language, then, different ways of thinking about animal behaviour emerged to describe and thereby characterise even the smallest of creatures (mice, especially). Focusing our gaze on even smaller forms, Sainath Suryanarayanan's paper then zoomed in on genes and genomes; the blueprints for coded patterns of biology and social behaviour. The analysis here was that ideas about social and environmental information and genetic variation interact in a way that impacts microorganisms (such as insects) as well as larger, more complex mammals; a powerful insight into scientific method for an age of experimentation that challenges the traditional concepts of inheritance and gives us new readings of self and society.

The final article brought bigger creatures to the fore. Richie Nimmo's account of humans and cattle enmeshed by the technologies of farming provided a fresh look at the dairy industry by flagging the importance of subjectivity in ethical and technical debates about milk production. Here the analysis was that in any observation from human-animal interaction, it is crucial to be mindful of power and its practical workings to show how the disciplining technologies of the material world, in this case milking machinery, risks de-humanising and de-animalising the actors involved. Helpfully, however, a theoretical corrective was provided by considering the networks that bring people, animals and technologies together through temporal and material assemblages, a concept that would no doubt frame and support a range of further cases.

Threading through these collected pieces is an explicit concern for the meaning of social, 
political and technical-material interactions in space - historic, contemporary and future. Together they open up important debates in human-animal relations and the technologies and materials which connect and disconnect the very different acting capacities of people and animals. In their own different findings and datasets, they demonstrate that these are not abstract questions because they are often mediated through organised and scientific settings - the laboratory, the farm-yard and milking parlour, the clinic, the aquarium. We may not see power, as such, but we can certainly perceive its effects in the structures, languages and disciplines of such settings. Hence, the issue provides valuable scaffolding to situate and explain how human and nonhuman bodies meet, interact, become close or repel one another and, more pressingly, how the knowledge and security of lived subject positions gain powerful ascendancy in - and through - organised science.

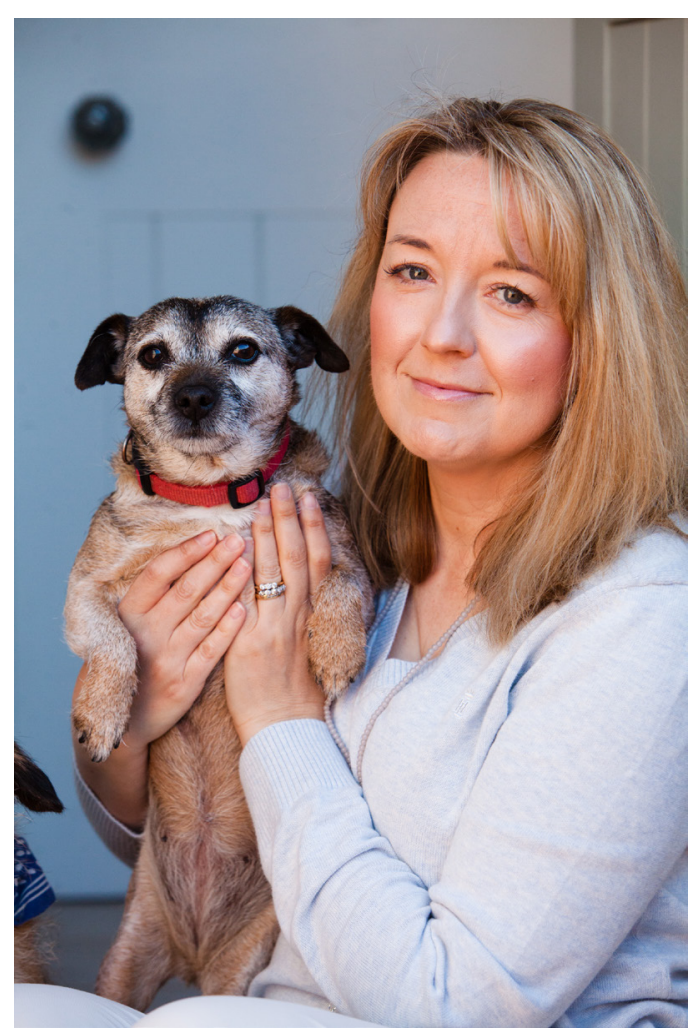

Figure 1 - The Author and her dog (Image by Lindsay Hamilton).

The important questions raised by these articles are far from resolved, however, and further scholarship is needed if we are to map and understand the plethora of commercial, scientific and organised meetings between the species. Not only would this enable us to better explain the most mundane of everyday examples (such as the ethnographic vignette provided at the outset - the "attacker" from which is pictured in Figure 1), but it would also supply analytic traction for moving forward on one of the biggest global challenges of the present age: how 
we (humans) should behave towards nonhumans and their habitats. There is no shortage of opinion on this most wicked of wicked problems, but there is a shortage of critical analysis, theoretical innovation and thickly descriptive empirical data.

This volume is a provocation, then, for a contemporary time period in which there are competing interests, mediated through increasingly complex socio-technical materials and subject to intense politics and activism. It turns a dark mirror upon the myth of value-free knowledge production and prompts us to remain critical and curious about how oppositional forces such as freedom and captivity, wildness and cultivation are managed through scientific methodologies and ways of seeing. Shooting to the heart of this quandary, these collected articles give us the theoretical and empirical frameworks to build understanding and, above all, to help navigate our own epistemological and ontological limits; the frustrations that human knowledges are restricted by our distinct species characteristics; our situation in historical time and the scientific technologies and methods that we hold dear. They also remind us that things can change. 